\title{
Assessment of strontium transport in clay medium by using a reactive transport modelling approach - an HP1 case study model
}

\author{
Dimitar Antonov
}

Geological Institute, Bulgarian Academy of Sciences, Acad. G. Bonchev Str., Bl. 24, 1113 Sofia, Bulgaria; e-mail:dimia@geology.bas.bg.

(Accepted in revised form: October 2017)

\begin{abstract}
Modelling of radionuclide transport in the geosphere is a key issue of the evaluation of safety of low- and intermediate-level radioactive waste (LILW) repositories. In Bulgaria, due to the operation of Kozloduy Nuclear Power Plant (NPP), a building of such facility is ongoing. The migration of ${ }^{90} \mathrm{Sr}$ was evaluated by simulation of flow and chemical modelling, performed with coupled numerical code HP1. The adsorption properties of the clays were implemented in the code by surface complexation reactions between strontium and iron oxides. The results were compared with another model performed with computer code HYDRUS 1-D, in which the adsorption properties of the medium were evaluated with the relevant for strontium distribution coefficient, $\mathrm{K}_{\mathrm{d}}$.
\end{abstract}

Antonov, D. 2017. Assessment of strontium transport in clay medium by using a reactive transport modelling approach - an HP1 case study model. Geologica Balcanica 46 (2), 23-26.

Keywords: strontium migration, modelling, adsorption properties, simulation results.

\section{INTRODUCTION}

Modelling of radionuclide transport has always been considered a key issue of the evaluation of safety of low- and intermediate-level radioactive waste (LILW) repositories. In Bulgaria, due to the operation of Kozloduy NPP, the construction of such facility is an ongoing process. The facility is situated in area with undulating relief, where the Brusartsi Formation (Kojumdjieva and Popov, 1988) represents the uppermost natural "barrier" against probable radionuclide migration, due to its properties predetermined by the prevailing clay content (Markova, 2003; Antonov and Mallants, 2008).

The most used way to assess contaminant transport is by using the convection-diffusion equation (CDE), whose terms describe mathematically the flow and solute transport into soils (Jury and Horton, 2004). Using CDE, the adsorption-desorption behaviour of soils (the ability of soils to retard a chemical element, including radionuclides, for a certain period of time) is examined by means of the so-called retardation factor, where the main term is an experimental parameter known as distribution or partitioning coefficient, $\mathrm{K}_{\mathrm{d}}$ (EPA, 1999a). The main problem is that the coeffi- cient's values are highly sensitive to the chemical conditions (mainly variations of $\mathrm{pH}$, redox potential and $\mathrm{CO}_{2}$ ). Therefore, this approach is inherently limited to describe contaminant migration when geochemical conditions are not constant.

On the other hand, in recent years, a new approach was developed: transport modelling implemented in coupled numerical codes (Steefel et al., 2005; Jacques and Šimůnek, 2005; Molinero et al., 2008). The coupled numerical codes integrate two main modules: a mathematical apparatus for the governing equations of the water flow part, including variably saturated medium (usually modified) and a mathematical apparatus for describing the chemical and geochemical reactions. The advantage of these codes, hence of the reactive transport modelling, is that the contaminant partitioning between the solute and solid (mineral) phases is described with equilibrium and kinetic type chemical reactions, which are a function of the geochemical conditions and mainly $\mathrm{pH}$ and redox potential.

This paper deals with a case study reactive transport modelling of a hypothetical vertical ${ }^{90} \mathrm{Sr}$ migration into the clays of the Brusartsi Formation in the region of Kozloduy Town (see Fig. 1). The flow and 


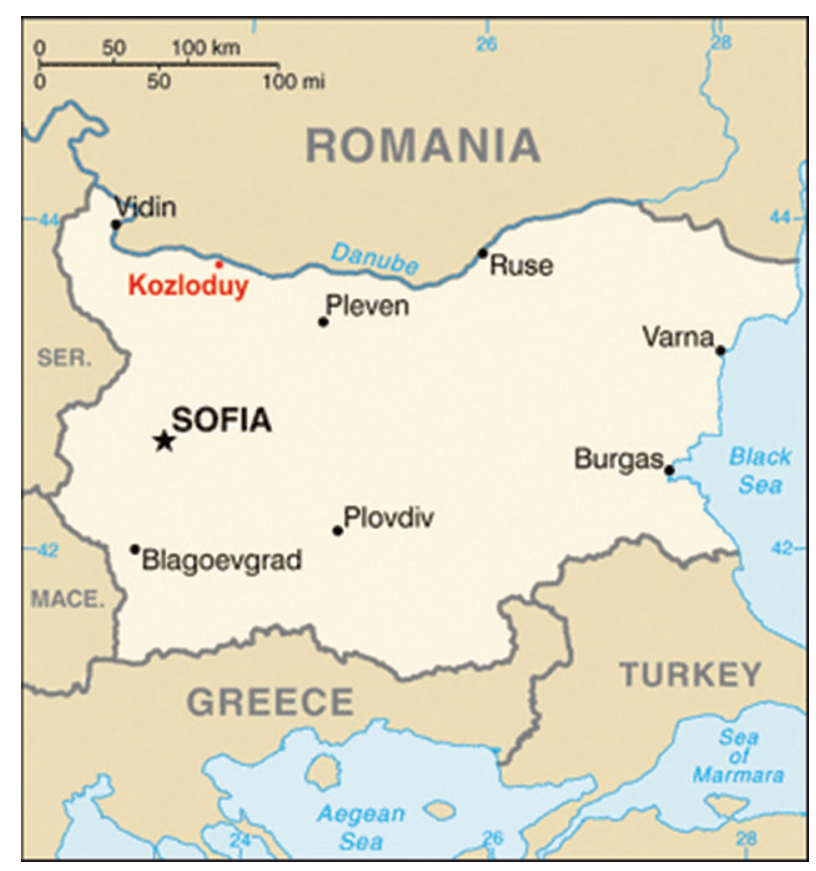

Fig. 1. Location of Kozloduy NPP site (source Perry-Castañeda Library, with additions).

chemical modelling were performed with coupled numerical code HP1 (Jacques and Šimůnek, 2005). The adsorption properties of the clays were implemented in the code by surface complexation reactions between strontium and iron oxides. The used methodology is similar to the one published by Jacques et al. (2008). The results were compared with another model performed with computer code HYDRUS 1-D (Šimůnek et al., 2008), in which the adsorption properties of the medium were evaluated with the relevant for the strontium distribution coefficient, $\mathrm{K}_{\mathrm{d}}$.

\section{METHODOLOGY}

\section{Numerical simulation code}

The HP1 incorporates modules simulating (1) transient water flow in variably saturated media; (2) transport of multiple components; and (3) mixed equilibrium/kinetic geochemical reactions. In the HP1 programme structure, the transport (flow) problems are connected with and described in the HYDRUS-1D module, and the geochemical problems are connected with and described in the PHREEQC module (Jacques and Šimůnek, 2005).

The general transport equation in HP1 (assuming homogeneous soil and steady-state water flux) is:

$$
\frac{\partial C_{l, i}}{\partial t}=\frac{\partial}{\partial x}\left(D_{i}^{w} \frac{\partial C_{l, i}}{\partial x}\right)-\frac{q}{\theta} \frac{\partial C_{l, i}}{\partial x}+R_{i}
$$

where $i\left(=1, \ldots, N_{m}\right)$ is the aqueous species number ( $N_{m}$ is the total number of aqueous species), $C_{l, i}$ is the aqueous concentration phase of the $i^{\text {th }}$ species $\left[\mathrm{M} \cdot \mathrm{L}^{-3}\right]$, $\theta$ is the volumetric water content $\left[\mathrm{L}^{3} \cdot \mathrm{L}^{-3}\right], q$ is the flux $\left[\mathrm{L}^{-\mathrm{T}^{-1}}\right], D_{i w}$ is the diffusion-dispersion coefficient of the $i^{\text {th }}$ species $\left[\mathrm{L}^{2} \mathrm{~T}^{-1}\right]$, and $R_{i}$ is the general sourse/sink term due to geochemical reactions for the $i^{\text {th }}$ species $\left[\mathrm{M} \cdot \mathrm{L}^{-3} \cdot \mathrm{T}^{-1}\right]$.

The sink/source term $R_{i}$ indicates heterogeneous (between two distinct phases, e.g., "solid-solute") equilibrium reactions and homogeneous (between same phases, e.g., "solute-solute") and heterogeneous kinetic reactions. Therefore, $R_{i}$ can represent any change of the system due to the chemical processes, which is one of the basic principles of the HP1 code.

In our case, the term $R_{i}$ combines three types of reactions: surface complexation process; cation exchange process; and first-order decay (degradation) process.

\section{Model elaboration and modelling implementation data}

The numerical simulations considered a vertical transport of strontium for 500 years in initially uncontaminated 20-m clay profile. Based on that, the elaboration of the model included the following main hydraulic and geochemical conditions and properties. The upper boundary condition (BC) was set to steady-state inflow of $0.0003 \mathrm{~m} \cdot \mathrm{d}^{-1}$ determined on the basis of hydraulic properties simulations on the annual rainfall distribution in the loess to clayey gravel Pliocene clay profile near the Kozloduy NPP region (Antonov et al., 2012). The lower BC was set to "free drainage" option. As a case study, the value of infiltrating strontium was set to $1 \times 10^{-7} \mathrm{~mol} / \mathrm{l}$. The bulk density of the Brusartsi Formation was set to $1800 \mathrm{~kg} \cdot \mathrm{m}^{-3}$ and dispersivity was equal to $0.1 \mathrm{~m}$. The geochemical properties of the clay medium were set arbitrarily, based on the data of Dzombak and Morel (1990), Markova (2003), Appelo and Postma (2007), and Jacques et al. (2008) as follows: (1) cation exchange capacity (CEC) equals $0.81 \mathrm{~mol} \cdot \mathrm{dm}^{-3}$; (2) weak sites of hydrous iron oxides $\left(\mathrm{Fe}_{2} \mathrm{O}_{3}\right)$ equal to $0.00287 \mathrm{~mol} \cdot \mathrm{l}^{-1}$; and (3) the decay constant of ${ }^{90} \mathrm{Sr}$ equals $6.64 \mathrm{~d}^{-1}$. Finally, the "phreeqcU.dat" database was used in order to perform the nonelectrostatic surface complexation model with its respective thermodynamic constants.

\section{RESULTS AND DISCUSSION}

The simulations of ${ }^{90} \mathrm{Sr}$ migration were performed for the periods of 50, 100, 300 and 500 years (Fig. 2). It was observed that, from the periods of 300 years and 500 years, the curves of strontium distribution coincide. Thus, after 300 years the concentration of the radionuclide at depth of $12 \mathrm{~m}$ becomes practically zero. The tendency could be explained with the equilibrium, 


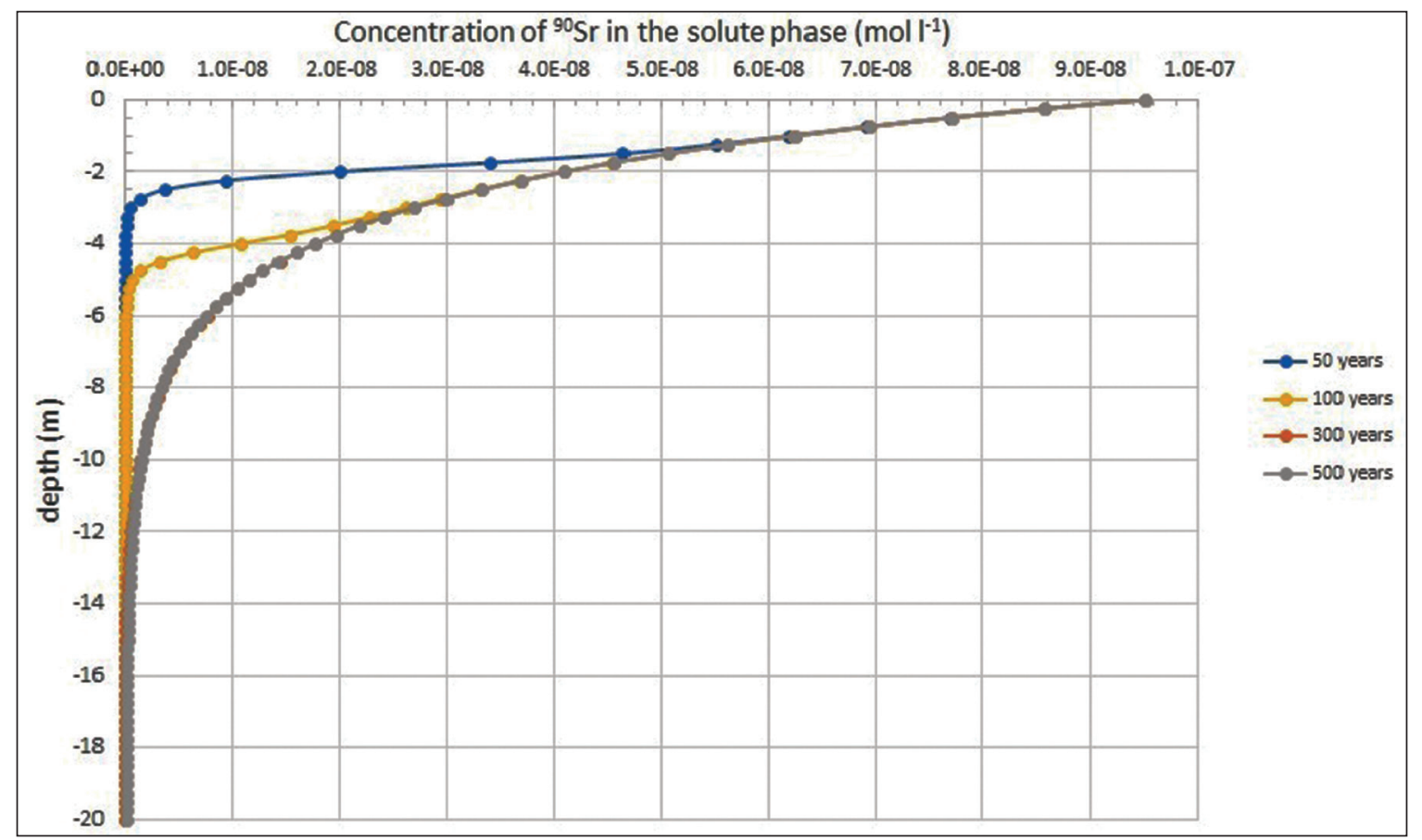

Fig. 2. Distribution of ${ }^{90} \mathrm{Sr}$ solution concentration through the profile at specific time periods by using HP1 code.

on one hand, of the decay process and, on the other, of the adsorption processes and infiltration.

In order to have a comparison of the determined strontium migration, another model was performed by using $K_{d}$ concept and HYDRUS1-D code. In the model, the hydraulic characteristics of the medium are the same as those in the previous one, only the retardation properties of the clays are evaluated by distribution coefficient concept. The exact value of $\mathrm{K}_{\mathrm{d}}$ was set to $0.39 \mathrm{~m}^{3} \cdot \mathrm{kg}^{-1}$ in accordance to EPA (1999b). The simulation results for the same time periods are shown in Fig. 3. In this simulation, the strontium concentra-

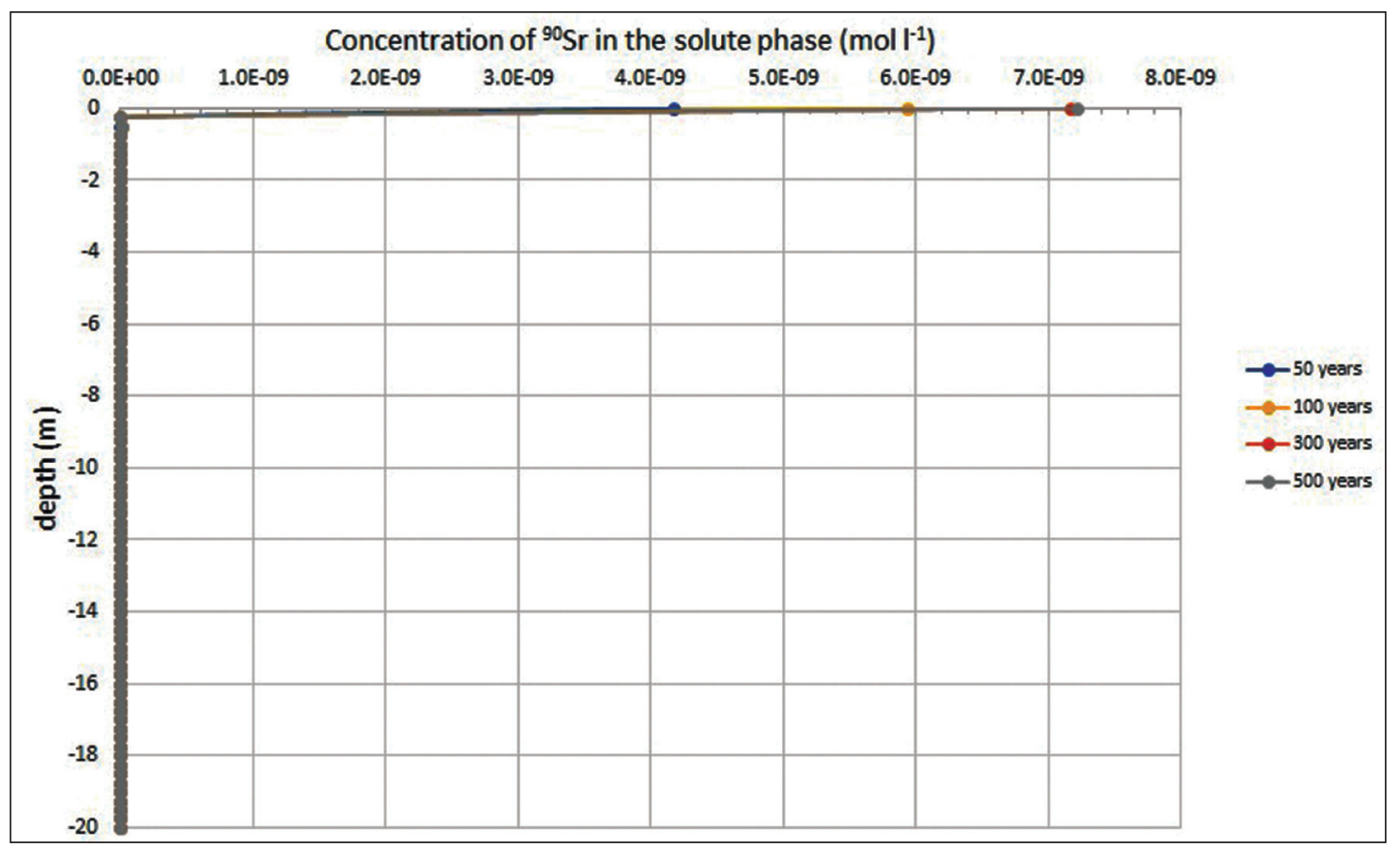

Fig. 3. Distribution of ${ }^{90} \mathrm{Sr}$ solution concentration through the profile at specific time periods by using HYDRUS1-D code. 
tion is practically negligible after the first $25 \mathrm{~cm}$ of the profile regardless of the time periods.

The patterns of the two models are quite different, which can be explained with the specificity of the two concepts. While the surface complexation reaction and cation exchange capacity model uses exact measured values of particular samples, the distribution coefficient model includes averaged strontium adsorption values determined by experimental migration studies.

\section{CONCLUSION}

An investigation of the strontium transport through clay medium of the Brusartsi Formation by using computer code HP1 was performed. The simulation results, based on vertical numerical model, show that, after 300 years, the concentrations of the radionuclide will be negligible after $12 \mathrm{~m}$ from the hypothetic surface. By using a different approach (with distribution coefficient), the possible migration of strontium is evaluated to only $25 \mathrm{~cm}$ from the surface in equal hydraulic conditions. Based on the number of studies which include and verify the distribution coefficient concept, the second model should represent more realistic strontium migration. On the other hand, the first model allows further integration of varying geochemical conditions. Therefore, there is a need for more detailed understanding of the mineralogical composition of the Brusartsi Formation to obtain more robust and reliable prognosis.

\section{REFERENCES}

Antonov, D., Mallants, D. 2008. Determination of soil hydraulic properties of potential low and intermediate level waste disposal sites in Bulgaria. Assistance to site selection and site evaluation for low and intermediate level waste disposal in Bulgaria. External Report, CO-90-99-122005, Studiecentrum voor Kernenergie/Centre d'Étude de l'énergie Nucléaire, 41 pp.

Antonov, D., Karastanev, D., Mallants, D. 2012. Determination of soil hydrological parameters of a multi-layered loess complex using HYDRUS-2D and field infiltration experiments. Compte rendus de l'Académie bulgare des Sciences 65 (12), 1717-1724.

Appelo, C.A.J., Postma, D. 2007. Geochemistry, groundwater and pollution (Second Edition). Balkema Publishers, Leiden, Netherlands, 649 pp.

Dzombak, D.A., Morel, F.M.M. 1990. Surface complexation modeling: Hydrous ferric oxide. John Wiley \& Sons, New York, 393 pp.

Environmental Protection Agency. 1999a. Understanding variation in partition coefficient, $K_{d}$, values (I), EPA 402-R99-004A, $212 \mathrm{pp}$.

Environmental Protection Agency. 1999b. Understanding variation in partition coefficient, $K_{d}$, values (II), EPA 402-R99-004B, $341 \mathrm{pp}$.

Jacques, D., Šimůnek, J. 2005. User manual of the multicomponent variably saturated transport model HP1: Description, verification and examples. Version 1.0. BLG-998.
SCK $\cdot$ CEN, Mol, Belgium, $91 \mathrm{pp}$

Jacques, D., Šimůnek, J., Mallants, D., van Genuchten, M.T. 2008. Modelling coupled hydrologic and chemical processes: Long-term uranium transport following phosphorus fertilization. Vadose Zone Journal 7, 698-711.

Jury, W., Horton, R. 2004. Soil physics (Sixth Edition). John Wiley \& Sons, Inc., Hoboken, New Jersey, 370 pp.

Kojumdjieva, E., Popov, N. 1988. Lithostratigraphy of the Neogene sediments in Northwestern Bulgaria. Palaeontology, stratigraphy and lithology 25, 3-26 (in Bulgarian).

Markova, R. 2003. Investigation on clays for radioactive waste disposal. Annual of the University of Mining and Geology "St Ivan Rilski" 46 (1), 321-326.

Molinero, J., Raposo, J.R., Galindez, J.M., Arcos, D., Guimera, J. 2008. Coupled hydrogeological and reactive transport modelling of the Simpevarp area (Sweden). Applied Geochemistry 23, 1957-1981.

Šimůnek, J., Šejna, M., Saito, H., Sakai, M. 2008. The HYDRUS-1D Software Package for Simulating the Movement of Water, Heat, and Multiple Solutes in Variably Saturated Media. Version 4.0. HYDRUS Software Series 3, Department of Environmental Sciences, University of California Riverside, Riverside, California, USA, 315 pp.

Steefel, C.I., DePaolo, D.J., Lichtner, P.C. 2005. Reactive transport modeling: an essential tool and a new research approach for Earth sciences. Earth and Planetary Science Letters 240, 539-558. 